\title{
Design of Intelligent Humidity Sensing Watering System Based on MCU
}

\author{
Chengjie ZHANG \\ Department of Information Engineering \\ Weihai Vocational College \\ Weihai, Shandong Province, China \\ e-mail: 382014179@qq.com
}

\begin{abstract}
In order to solve the problem of watering flowers timely in family, an intelligent automatic watering systems is designed, which can realize intelligent watering for different soil moisture needs of different kinds of flowers. It adopts FC28 soil moisture sensor to detect soil humidity and uses the AT89C52 MCU as control chip to compare the humidity signal with the preset threshold , and control the pump motor for watering based on the results of the comparison.
\end{abstract}

Keywords-MCU; sensor; LCD; A/D; intelligent

\section{INTRODUCTION}

With the improvement of domestic consumption level and quality of life, home garden market is booming. But for the quickening pace of life, flower care has become a problem-the key is watering. Studies have shown that more than $80 \%$ of flower's deaths due to not watering in time. Some plants have strict requirements for humidity. Watering excess, the roots of the plant will rot easily[1],which affects the normal growth of plants.

In order to make people easily grow flowers at home, this paper designs an intelligent humidity sensing watering system, which can monitor the soil moisture in real time and water flowers timely. And It allows users to customize the soil moisture according to different kinds of flowers. In a word, the system has brought great convenience for family gardening.

\section{OVERALL DESIGN OF SYSTEM}

The main functions of the system include: automatic monitoring of soil moisture, information display and automatic watering. First the FC-28 moisture sensor detects soil humidity, and the result is sent to the ADC0832 chip, which convert analog signal to digital signal. Then the MCU[2,3] displays the moisture information on the LCD, at the same time the program determines whether to water flowers. It compares the soil moisture to the preset threshold of moisture, if the soil moisture is lower than the lower limit value, the relay is turned on, the water pump start watering. When the soil moisture reaches the upper limit value, it will stop watering. The overall design of the system is shown in figure 1.

\section{HARDWARE DESIGN}

\section{A. Circuit of System}

The system is mainly composed of soil moisture detection circuit, keyboard, LCD liquid crystal display circuit, alarm circuit, water pump control circuit and so on The circuit of the system is shown in Figure 2.

\section{B. Circuit of Soil Moisture Detection}

The humidity sensor FC-28 is used to detect the roil humidity[4]. It has two stainless steel water proof probe, with nickel plating processing surface avoiding rust contacting with soil, so it can be buried in soil for a long time. Soil moisture detection module circuit is shown in figure 3.J1 is two probe, inserted in the soil.AC pin is used to collect voltage. When the soil moisture is too small, the resistance between the probe close to infinity, however when the soil moisture is too large, the resistance between the probe will be reduced to thousands or even hundreds ohms. LM393 is a comparator. Setting a standard value by the R1, when the humidity is high, the output of OUT pin is low, on the contrary, the output is high l. Light L1 indicates that the circuit is switched on. Light L2 represents the state of 
humidity. When the humidity is small, L2 is off, otherwise $\mathrm{L} 2$ is on.

\section{Circuit of Alarm and Automatic Water Module}

Alarm and automatic watering module circuit is shown in figure 4. The working voltage of the pumping motor is $5 \mathrm{~V}$ as the same as microcontroller's [5], so they share a common ground wire. Another pin of the pumping machine is connected with the triode. The base of the triode is connected to the control pin of the microcontroller. The water pump is controlled by the triode. When the control pin of the microcontroller is in low level, triode switches into conduction, and pumping machine starts working. When the control pin is in high level, the transistor is in saturation state, and the pumping motor stops working. The working principle of the alarm buzzer is the same as the automatic watering module's.

\section{Circuit of Button Module}

Button module circuit is shown in figure 5. Key module realize setting of system mainly through three buttons, including mode key, set key and value added key. Mode key allows the liquid crystal display module to display different content in different display mode. Setting key can control parameters, such as humidity, time and duration. In setting mode, the value of parameters can be changed by value added key.

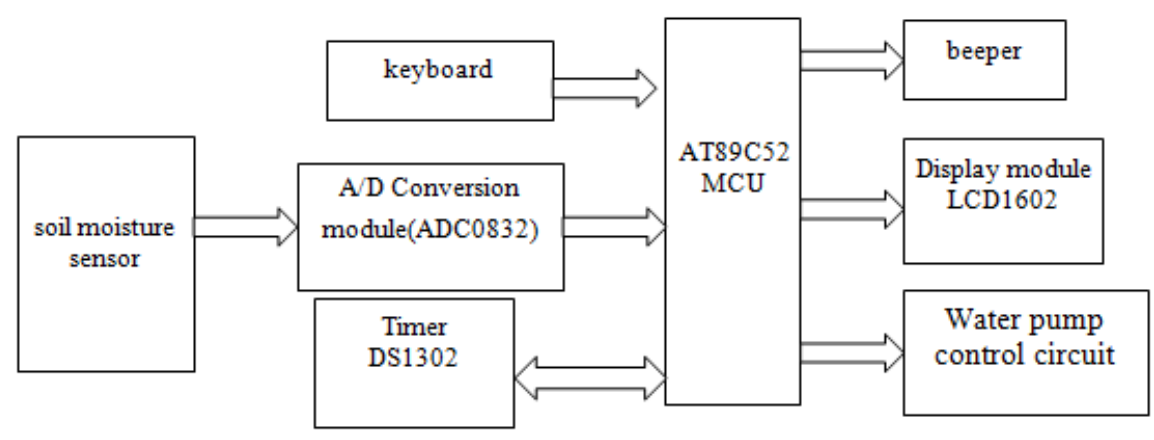

Figure 1. Diagram of the system overall design

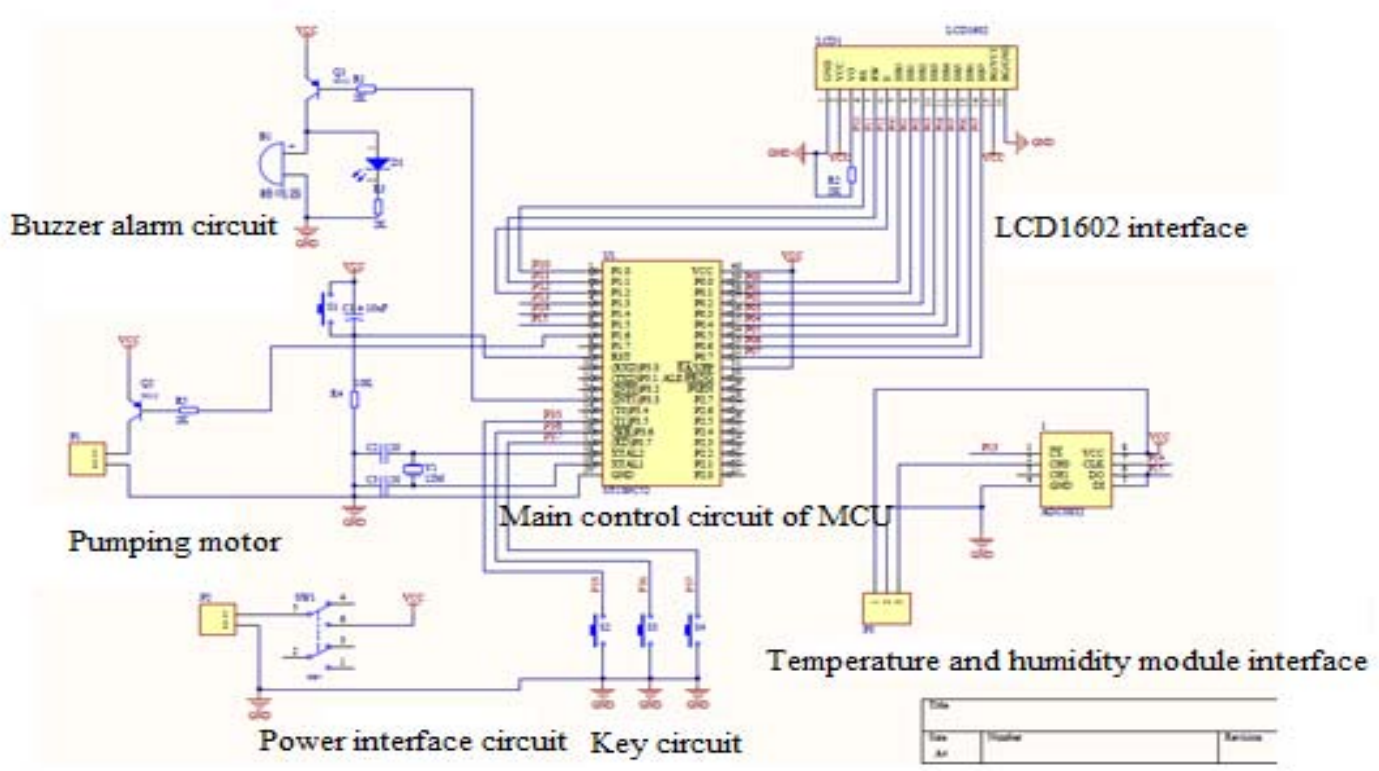

Figure 2. Automatic watering system circuit 


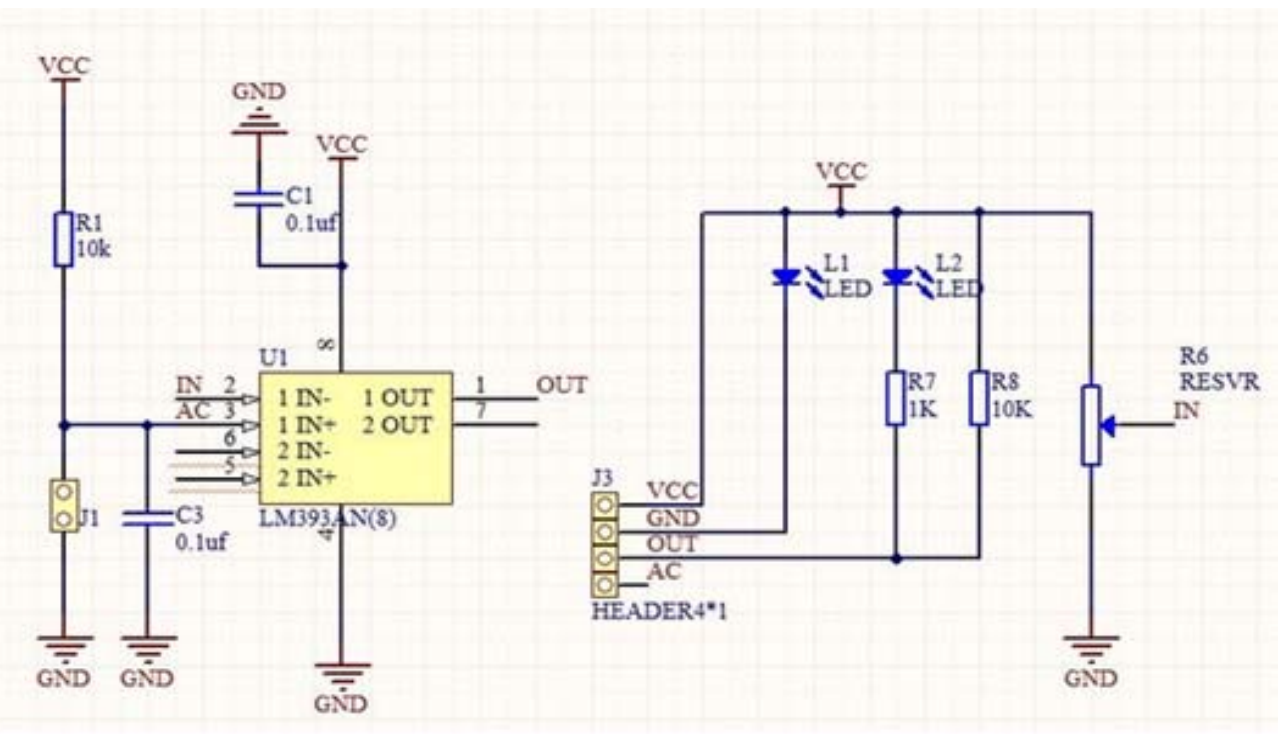

Figure 3. Soil moisture detection circuit

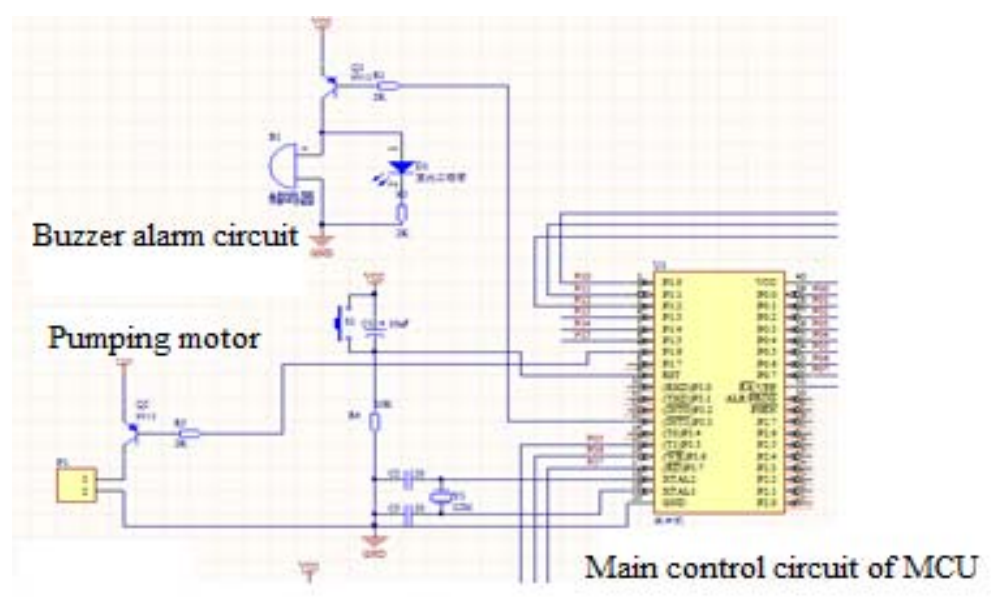

Figure 4. Alarm and motor drive circuit

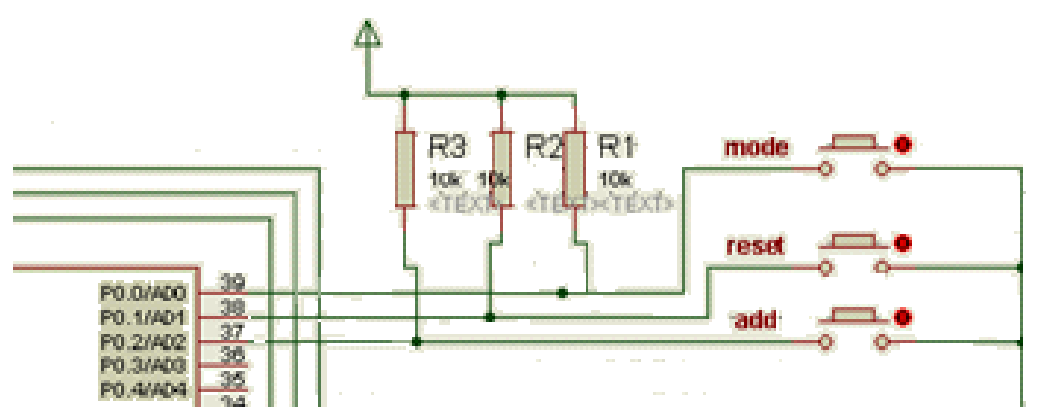

Figure 5. Key circuit 


\section{SOFTWARE DESIGN}

The system software is composed of the initialization subroutine, the display subroutine, the flower kinds selection subroutine, the soil moisture detection subroutine, the data processing subroutine, the alarm subroutine and so on. The flow chart of the main program is shown in Figure 6. Because different kinds of flowers grow in different humidity conditions, the water requirement range of different flowers is prestored in a form in advance, which is written in a certain area of ROM for use later. First, the initialization function is called as soon as the system started, and the initial interface is displayed. Then, user can choose the kind of flowers and the program looks up the flower's humidity range in the prestored form according to the flowers sort user choosed. Finally the soil moisture data acquisition function is called, collecting the current soil humidity value and analyzing it by data processing program. When the humidity value is less than the preset value, the water pump motor drive function is called and begins to water until the humidity value reaches the upper limit. In order to reduce unnecessary work, the soil moisture was collected every hour when not watering, otherwise it was collected every minute.

\section{IMPLEMENTATION AND EXPERIMENT}

The system was installed on a flowerpot with a healthy plant. The device was running in a room with bright light and managed by the system, we found that the plant grew well 30 days later. During this period, using moisture detector to detect soil moisture random, the value is similar to which detected by the humidity sensor. The results of the comparison are shown in Table 1.

TABLE I. The VAlue of the Collected Humidity AND the ACTUAL HUMIDITY

\begin{tabular}{ccc}
\hline \hline $\begin{array}{c}\text { humidity } \\
\text { examination }\end{array}$ & Soil Humidity(\%) & $\begin{array}{c}\text { Soil Humidity after } \\
\text { watering(\%) }\end{array}$ \\
\hline humidity sensor & 8.7 & $32.5 \%$ \\
Humidity detector & 9.1 & $35.4 \%$ \\
\hline \hline
\end{tabular}

Through data analysis, it is discovered that although the data is close to the actual reading, but there are still some errors. Partly because the sensor itself has a certain error resulting data unstable; and the other part is not for average operation. To improve the accuracy of data we can use two soil moisture sensors, one is used to measure the soil moisture at the bottom of the pot, and the other is used to measure the soil moisture at the top of the flower pot, then calculate the average, thus the result will be closer to the real value, and it can improve the reliability of the data effectively.

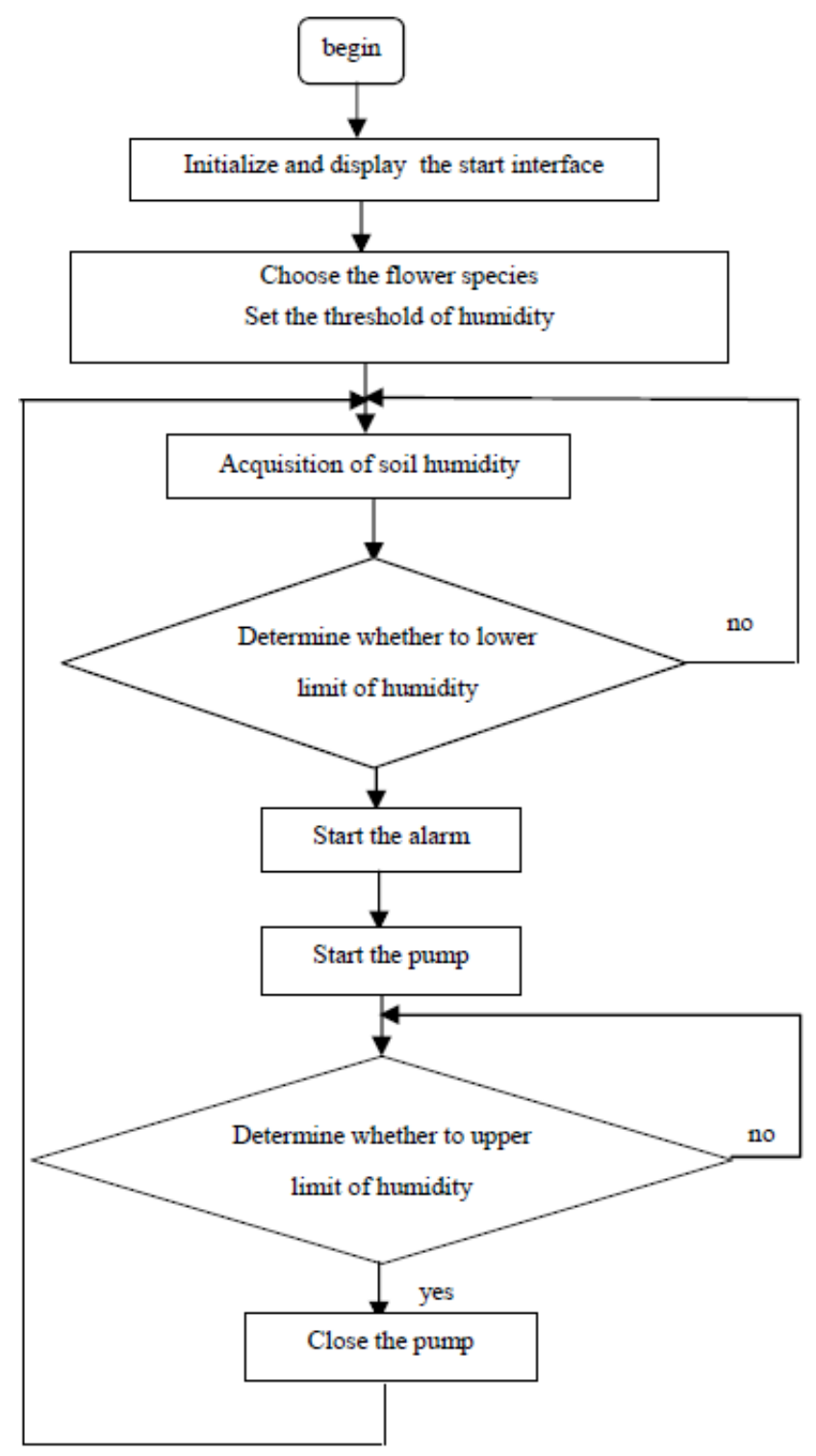

Figure 6. Main program flow chart 


\section{CONCLUSION}

This paper designed an intelligent watering system,using the AT89C52 single chip microcomputer as control chip. The system can realize intelligent watering according to the type of flowers and the soil moisture. Compared with the current market sales of the automatic watering system, the system has low cost, simple installation, is very suitable for the ordinary family, it also can be used in the greenhouse, flowers, nursery, lawn etc. In a word it has high application value.

\section{REFERENCES}

[1] Zhao Li, Zhang Chenlin, Design and Implementation of Intelligent Watering System Based on SCM, Journal of Changchun University, vol.22(2012) 650-651.

[2] Cheng Jie, He Chen, Design and Implementation of the Temperature and Humidity Detection, Journal of Instrument Technology, vol.6(2016)56-58.

[3] Cao Changyong, Cao Weijian, Design of digital temperature and humidity monitoring system for grain depot based on AT89C52 and DHT11, Journal of Qiqihar University,vol.30(2014)1-33.

[4] Tan Xiaogang, Gao Guowei, Zhang Liqiang, Zhao Yunjie, Design of an agricultural soil humidity controller based on Arduino platform, Journal of Sensor World,vol.22(2016)30-34.

[5] Li Yao, Zheng Hanfeng, Liu Wei, Li Jin, the design of intelligent watering system, Journal of Industrial Control Computer, vol.29(2016) 47-48. 